\title{
Recognition and Effective Handling of Negations in Enhancing the Accuracy of Urdu Sentiment Analyzer
}

\author{
Neelam Mukhtar'a, Mohammad Abid Khan'1b, Nadia Chiragh², \\ Asim Ullah Jan ${ }^{3}$, Shah Nazir ${ }^{4}$ \\ RECEIVED ON 14.01.2019, ACCEPTED ON 15.08.2019
}

\begin{abstract}
Although work has been done in Urdu Sentiment Analysis by researchers but still there is a lot of room for improvement in the form of achieving higher accuracy. Therefore, in this research, the accuracy of Urdu Sentiment Analysis in multiple domains is enhanced by dealing negations using Lexicon-based approach, one of the broadly used approaches for performing Sentiment Analysis. Negations in Urdu Sentiment Analysis are particularly focused in this research because of their effective role in Sentiment Analysis. Both local and long distance negations are considered. For achieving this goal, a corpus with 6025 Urdu sentences, from 151 blogs that belong to 14 different genres is taken in which use of negations is carefully observed. Two major steps are taken in this regard. First, to deal with the morphological negations, this type of negations is included in the negative word file of the Urdu Sentiment Lexicon developed for performing Sentiment Analysis of Urdu blogs. Secondly, rule-based approach is used for handling the implicit and explicit negations. Rules are designed that can deal with both implicit and explicit negations effectively. Implementation of these rules increased the accuracy of Sentiment Analyzer from $73.88 \%$ to $78.32 \%$ with $\mathbf{0 . 7 4 5 ,} 0.788$ and 0.745 Precision, Recall and Fmeasure respectively, which is statistically significant improvement.
\end{abstract}

Keywords: Sentiment Analysis, Implicit Negations, Explicit Negations, Morphological, Negations, Urdu Sentiment Analyzer.

\section{INTRODUCTION}

$\mathrm{N}$ egations, also called negation particles, vary from language to language and are used for negating statements or parts of statements. It is essential to handle these negations carefully while performing Sentiment Analysis (SA) by computer. Thus, identifying the scope of negations becomes very important.

The polarity of a complete sentence or part of a sentence is normally reversed by the negation of words
[1]. Negation turns an assertion into its opposite [2]. Understanding of the negation features help a lot in the improvement of performance [3].

Broadly, different forms of negations can be divided into two main groups i.e. local negation and long distance negation [4]. Negations can be found immediately before or after the positive or negative word/term (e.g. "not bad") or there can be longer distance dependencies (e.g. "does not seem very difficult") or there can be negation of the subject itself (e.g. "no one considers it easy"). Even sometimes,

\footnotetext{
${ }^{1}$ Department of Computer Science, University of Peshawar, KPK, Pakistan.

Email: asameen_gul@yahoo.com (Corresponding Author), babid_khan1961@yahoo.com,

${ }^{2}$ University of Agriculture, Peshawar, Pakistan. Email: nadiachiragh@ yahoo.com

${ }^{3}$ Department of Computing, Abasyn University, Peshawar, Pakistan. Email: asim.ibms@gmail.com

${ }^{4}$ Department of Computer Science, University of Swabi, KPK, Pakistan. Email: snshahnzr@ gmail.com
}

This is an open access article published by Mehran University of Engineering and Technology, Jamshoro under CC BY 4.0 International License. 


\section{Recognition and Effective Handling of Negations in Enhancing the Accuracy of Urdu Sentiment Analyzer}

negations change their role from negation to intensification (e.g. "not only intelligent but also hardworking") [4]. The frequency of negation in a sentence can be more than once. In such a situation, the two negations instead of cancelling each other may result in a negative meaning [5]. Furthermore, negation can change the meaning of a sentence without being used explicitly [6]. For example, "the company has introduced a new mobile; it was the first and last attempt".

A complete summary report regarding performance of the company, $10-\mathrm{K}$ reports, that is annually submitted to the security and exchange commission, shows that companies usually use positive words while framing negative news and seldom use negative words for positive news [7]. The results of positive words are mixed due to the wrapping of negative phrases in positive words [8].

Negations can change the sentimental orientation of the other terms occurring in a sentence [9]. Negations affect the polarity of a sentence, if a sentence has such words. The polarity of a sentence may be inverted due to negations [10]. Negations are important linguistics that affects the polarity of other associated words. To improve the performance o sentence level SA, negations should be handled effectively [11].

Due to the importance of negations mentioned above, they are particularly focused, identified and handled successfully in this research for improving the performance of Urdu Sentiment Analyzer in the form of achieving higher accuracy than the one that was achieved when negations were not handled.

For detecting the scope of negation, the existing approaches can be divided broadly into two categories:

(1) Rule-based algorithms (Lexicon-based approach where no prior training data is required but lexicons are used)

(2) Machine learning algorithms (e.g. Supervised Machine Learning where an annotated corpus for training and testing the classifier(s) is required).

In case $\mathrm{SA}$ is to be performed in multiple domains, then large amount of annotated data is required while using Supervised Machine Learning approach for the training of classifiers. This is not only a laborious task but also very time consuming and costly. The approach may not perform well if applied to a domain for which it is not trained. On the other hand, no training data is required in case of Lexicon-based approach. A wide coverage lexicon and an efficient algorithm are required in this approach, which are not much time consuming and costly.

\subsection{Explicit Research Objectives}

- To identify different types and forms of negations in Urdu.

- To handle morphological, implicit and explicit negations while performing Urdu Sentiment Analysis.

- To enhance the accuracy as compared to the previous work done in Urdu Sentiment Analysis after successfully handling negations.

\subsection{Types of Negations in Urdu}

Negations are frequently used in Urdu. Some commonly used negation particles in Urdu are $\sim$ (nah i.e. not), نا (naa i.e. no), نبين (nahi i.e. no), مغنب (mat i.e.

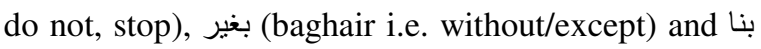
(bena i.e. without/except). Different types of negations can appear in text [12]. These types are e.g. sentential negation, constituent negation, multiple negation and negation in coordinate structure. These types are discussed one by one in detail.

\subsubsection{Sentential Negation}

Sentential negation means the negation of the whole sentence. Negation particles are used for expressing sentential negation. Examples are ن (nah i.e. not), نا (naa i.e. no), نبير (nahi, no), بغير (baghair i.e. without/except) and sت (mat i.e. do not, stop). Consider examples of sentential negations that are using these negation particles:

$$
\text { شهبر كا انفر السظركجر جند كهنظون كى بارش كا بوجه نـ }
$$

Sheher ka infrastructure chand ghanton ki barish ka bojh nah utha saka.

The city's infrastructure collapsed after few hours of rain.

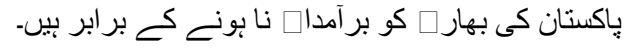


Pakistan ki Bharat ko baraamdaat naa honay ke barabar hain.

Pakistan's exports to India are almost negligible.

$$
\text { كرنيس- }
$$

Dosray yeh ke khawateen kabhi taiz raftari ka muzahira nahi karteen.

Secondly, women never act in hast.

$$
\text { إدهر أدهر مت ديكهين- }
$$

Idher udhar mat dekhen.

Stop looking here and there.

$$
\begin{aligned}
& \text { ملى بهر مين } 60 \text { فيصد قيدى بغير عدالتى كارروائى }
\end{aligned}
$$

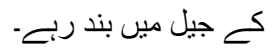

Mulk bhar mein 60 feesad qaidi baghair adalti karawai ke jail mein band rahay.

Sixty percent prisoners across the country were jailed without proper trial.

In (i), (ii), (iii), (iv) and (v), sentences are negated by the use of negations i.e. ن (nah i.e. not), نا (naa i.e. no), نهيب (nahi i.e. no), مت (baghair i.e. without/except) respectively.

\subsubsection{Constituent Negation}

This type of negation is used in order to negate particular constituent(s). Usually, the negated constituents are followed by negative particles [12]. Commonly used constituent negation particles are (naa i.e. no), نهيي (nahi i.e. no), سوا (siwa i.e. except) and مت (mat i.e. do not/stop). Consider the following examples:

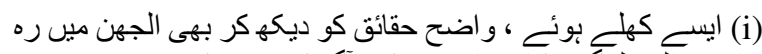

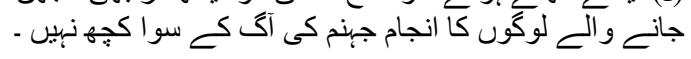

Aisay khulay huwe, wazeh haqayiq ko dekh kar bhi uljhan mein reh jane walay logon ka anjaam jahannam ki aag ke siwa kuch nahi. In spite of such obvious facts, confused people have no destination except hell.

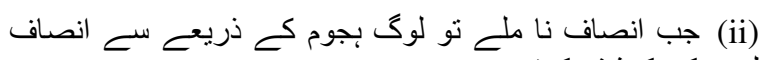

$$
\begin{aligned}
& \text { لين كى كوشش كرته بين. }
\end{aligned}
$$

Jab insaaf naa miley to log hajoom ke zariye se insaaf lainay ki koshish kartay hain.

When Justice is denied, people use to get their right through gathering a crowd.

In (i) and (ii), constituents are negated by negation particles i.e. سوا (siwa i.e. except), نهيي (nahi i.e. no) and (naa i.e. no) respectively.

\subsubsection{Multiple (Consecutive) Negation Particles}

The occurrence of double negations is also observed in Urdu language in order to emphasize more on a certain point. Consider the following examples taken from the collected Urdu corpus:

$$
\text { آئى- نهيي نـ بات سمجه مين (i) }
$$

Nahi Baat samajh mein nah aayi.

I did not understand.

سوجتا بوب، نهين نهي خر ابيان سب كـ سامنح لائى

Sochta hoon, nahi nahi kharabian sab ke samnay layi jani chahiye.

I think deficiencies should be publicly known.

In (i) and (ii), sentences are negated with more emphasis by using multiple consecutive negations i.e. respectively.

\subsubsection{Negations Found in Coordinate Structures}

In case of situations like "neither-nor" in English, negations in Urdu, usually appear in the beginning position but sometimes may occur in the middle as well. Consider the following examples:

نا يهلى بيوى سـ بن يائى اور نا اب دوسرى بيوى ســنباه بو ربا $-\subset$

Naa pehli biwi se ban paayi aur naa ab doosri biwi se nibah ho rahaa hai.

He was neither adjusted with the first wife nor with the second one now.

(Normally, this is used without the first ن but the meaning remains the same).

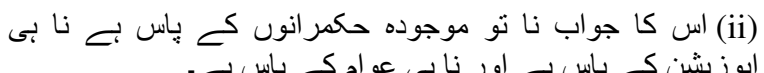




\section{Recognition and Effective Handling of Negations in Enhancing the Accuracy of Urdu Sentiment Analyzer}

Is ka jawab naa to mojooda hukmraanon ke paas hai naa hi opposition ke paas hai aur naa hi awam ke paas hai.

The answer to this is neither with the government nor the opposition nor the public at large.

In (i), the first (naa i.e. no) appears in the beginning and the second one in the middle. In (ii), ن (naa i.e. no) does not appear in the beginning, although it occurs three times.

\subsection{Forms of Negation in Urdu}

Negations whether sentential, constituent or multiple can occur in three main forms in Urdu. These three forms are identified by Syed et al. [12], and are discussed one by one.

\subsubsection{Morphological Negation}

Negations can be morphological where negations are attached as prefix or suffix to a word e.g. $\_$(bay i.e. without) and Consider the following examples:

$$
\text { i. ان مين سـ زياده نر بـ گهر، بـ روزكار لوگ بي. }
$$

Un mein se ziyadah tar be-ghar, be-rozgaar log hain. Most of these people are homeless and unemployed.

$$
\text { ii يقيناً اس كا جو اب دينا نامدكن بـح- }
$$

Yaqeenan is ka jawab dena naa mumkin hai.

For sure, this (question) is impossible to answer.

In (i) and (ii), morphological negations are used by using the prefixes $\longrightarrow$ (bay i.e. without) and (naa i.e. no) respectively. To handle this type of negation, words starting with $\_$(bay i.e. without) and $L$ (naa i.e. no) (usually acting as negative) are included in negative word list.

\subsubsection{Implicit Negation}

Negation can be implicit as indicated by e.g. كم (kam i.e. low/less). Consider the following example:

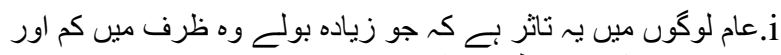

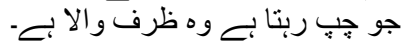

Aam logon mein yeh ta-assur hai ke jo ziyadah bolay woh zarf mein kam aur jo chup rehta hai woh zarf wala hai.

A common impression among the people is that the one who talks more is immature whereas the less talkative one is considered as more mature.

In (i), the implicit negation in the form of 5 (kam i.e. low/less) is used. This type of negation is handled by taking two steps. First, implicit negations are kept in separate files and then a rule is formulated which can work for it.

\subsubsection{Explicit Negation}

Negation can be explicit e.g. نهيي. Consider the following examples:

$$
\text { i تقليد بُرى نهيب بلكى اندهى تقليد بلاكت خيز بــ- }
$$

Taqleed burii nahi balkay andhi taqleed halakat-khaiz hai.

Following someone is not bad but following someone blindly is deadly.

$$
\text { ii }
$$

Unhain yeh baat pasand nah aayi.

They did not like this argument.

In (i) and (ii), two most commonly used negations are used i.e. نهيي (nahi i.e. no) and ن ن (nah i.e. not) respectively. Explicit negation is the most common form of negation. To handle this type of negation, two steps are taken. First, all such negations are included in negation file and secondly, a rule is formulated.

Rest of the paper is organized as follows. Related work is presented in Section 2. Material and methods are discussed in Section 3. Results and discussion are presented in Section 4. The paper is concluded in Section 5.

\section{RELATED WORK}

Several studies can be found on the detection of negations while analyzing sentiments analysis $[1,3$, 13]. The approach of n-grams for negation detection is used by [14]. The impact of negation tagging in French, English and Dutch opinion mining is studied 


\section{Recognition and Effective Handling of Negations in Enhancing the Accuracy of Urdu Sentiment Analyzer}

with the conclusion that negation detection by using language specification is helpful [15]. Sentiment Analysis is also performed by handling intensifiers words and negations together [16].

The sentiment of each word that occurred after a negation is inverted till the next punctuation token [17]. Positive scores are assigned to expressions that are positive and negative scores to negative expressions. The polarity score is simply inverted in case of the presence of negation [18]. Negation is modeled on the basis of three features on polar expressions [3]. These three features are "shifter feature" (the occurrence of different polarity shifters e.g. "little"), "polarity modification features" (the words that are not negations explicitly but they modify the polarity e.g. "lack") and "negation features" (if there is a negation before polar expression).

For detecting negations, a list of negation cue is used [19]. The scope of negation is then determined by utilizing the syntax tree of the sentence (with a negation). Negations are thus analyzed by using different ways e.g. Dependency Tree, Parts-of-Speech and Bag-of-Words. The tactful combination of these approaches can lead to much better result compared to their use in isolation [20].

Most of the researchers have worked on SA using languages other than Urdu. Few researchers have worked in Urdu SA [21]. Urdu corpus and lexicon are developed by researchers [22-25]. A sentimentannotated lexicon is developed manually [26]. The developed Urdu lexicons are either publicly unavailable or cannot be used for Urdu Sentiment Analysis. Urdu SA is performed by different researchers using Lexicon-based approach [27-29]. Urdu SA is performed, where subjective expressions called Sentiunits are extracted that automatically cater for the effect of negations and negations are handled within the phrase [29]. The performance of the developed Urdu Sentiment Analyzer by these authors is domain specific and the annotated lexicon needs extension by including words from multiple domains. Further, the authors [29] have used three sets of data and have achieved satisfactory results but still further enhancement in the performance is needed.

\section{MATERIALS AND METHODS}

Different steps taken are discussed one by one:

\subsection{Urdu Annotated Corpus}

A corpus with 6025 sentences was already collected in yet another study conducted by few authors of this research. These sentences were taken from 151 online blogs belonging to 14 different genres. For labeling these sentences as positive negative and neutral, expertise of two human annotators were hired. Maximum vote strategy was adopted. In case of agreement on the same label by the two annotators sentence was labeled accordingly. In case of disagreement between the two for a particular sentence, the sentence was considered as a tied sentence. All such sentences were collected and annotated by the third annotator. Depending on the decision of the third annotator (whether he agreed with the first or second annotator), the sentence was labeled. The sentence was discarded where the third annotator neither agreed with the first annotator nor with the second annotator. After this step, 1876 sentences were labeled as positive, 2753 sentences as negative, 1388 sentences as neutral and 8 sentences were discarded due to disagreement between the annotators [30].

To observe the use of different negations discussed above, negations and their frequency is carefully observed in the collected corpus. Table 1 shows commonly used negations and the number of times they are used in the corpus.

\begin{tabular}{|c|c|c|}
\hline \multicolumn{2}{|c|}{ Table1: Negations Along with their frequency } \\
\hline S.No & Negation & $\begin{array}{c}\text { Frequency } \\
\text { (Num) }\end{array}$ \\
\hline 1 & $\sim$ (nah i.e. not) & 395 \\
\hline 2 & (nahi i.e. no) & 1090 \\
\hline 3 & $\begin{array}{c}\text { (naa i.e. no) } \\
\text { (mat i.e. do } \\
\text { not/stop) }\end{array}$ & 56 \\
\hline 4 & $\begin{array}{c}\text { Im (siwa i.e. } \\
\text { except) }\end{array}$ & 5 \\
\hline 5 & & 21 \\
\hline
\end{tabular}

From Table 1, it is clear that the most commonly used negation in Urdu is نبي followed by $\sim$ ن. 


\subsection{Urdu Sentiment Lexicon}

A wide coverage Urdu lexicon was developed by first collecting positive and negative words from different sources. Urdu lughat (http://urdulughat.info/) was then used to expand the collection. Positive and negative words were kept in separate files. Intensifiers, negations and context-dependent words were extracted from the Urdu corpus. The tagger (http://www.cle.org.pk/), which is developed by Center for Language Engineering (CLE), University of Engineering and Technology (UET) Lahore, was used for assigning POS to the collected words. For maximum reliability, Urdu lughat was once again used to verify the POS assigned by the tagger. An Urdu Sentiment Lexicon (SL) was finally created with 11,739 negative words and 9,578 positive words, along with separate files for intensifiers, contextdependent words and negations [31].

In order to handle morphological negations for this study, a large number of such words are included in the negative word file in this lexicon.

\subsection{Urdu Sentiment Analyzer}

The algorithm, already developed by the authors (Ph.D thesis), is based on rules for handling different issues (e.g. negations, intensifiers and context-dependent words), that arises while classifying the sentences. Numbers of rules are incorporated using Java JDK 6, Netbeans environment to develop an Urdu Sentiment Analyzer (in this research, only the rules related to negations are focused). The Urdu Sentiment Analyzer takes an Urdu blog with several sentences as input. Words in each sentence are searched in different files e.g. positive, negative and negations and are assigned polarities according to rules. At the end of the processing of a sentence, all polarities in a particular sentence are added. If the sum is greater than 0 , the sentence is declared positive. If the sum is less than 0 , the sentence is assumed negative. If the sum is equal to 0 , the sentence is considered as neutral i.e.

$$
\mathrm{X}=\sum_{\mathrm{i}=1}^{\mathrm{m}} \mathrm{W}_{\text {poli }}
$$

where $\mathrm{m}$ is the total number of positive and negative words surrounded by negations in each sentence and
$\mathrm{W}_{\text {poli }}$ (discussed in the next section) is the polarity value assigned to each positive and negative word with negations according to rules.

If $X>0$, the sentence is declared as positive.

If $X<0$, the sentence is declared as negative.

If $\mathrm{X}=0$, the sentence is considered as a neutral sentence.

At the end, final conclusion is displayed which shows whether maximum number of sentences in the blog are positive, negative or neutral.

\subsection{Rules for Handling Implicit and Explicit Negations}

After a particular sentence (with negation) is provided to the system for processing, then each word in the sentence is checked in the developed Urdu lexicon which has the following files:

$\mathrm{W}_{\mathrm{pos}}=\{$ list of positive words $\}$

$\mathrm{W}_{\text {neg }}=\{$ list of negative words $\}$

$\mathrm{W}_{\text {expnegats }}=\{$ list of explicit negations $\}$

$\mathrm{W}_{\text {impnegats }}=\{$ list of implicit negations $\}$

$\mathrm{W}_{\text {int }}=\{$ list of intensifiers $\}$

$\mathrm{W}_{\mathrm{sw}}=\{$ list of special words $\}$

In general

$\mathrm{W}_{\mathrm{pol}}=\left\{1\right.$, if $\left.\mathrm{S} \in \mathrm{B} \wedge \mathrm{W} \in \mathrm{W}_{\mathrm{pos}}\right\}$

$\mathrm{W}_{\text {pol }}=\left\{-1\right.$, if $\left.S \in B \wedge W \in W_{\text {neg }}\right\}$

where $\mathrm{W}_{\text {pol }}$ is the polarity assigned to a positive/negative word. $\mathrm{W}$ is a word, $\mathrm{S}$ is a sentence from blog(s), B. Specific rules for handling negations are discussed below:

(1) A positive word will have negative polarity collectively, if there is a negation word before or after this word. The distance between words may vary from one word to several, e.g. نش خود كو بدايت (nah khud ko hidaayat panay i.e. not guided himself/themselves) where بدايت (hidaayat i.e. guidance/instruction) is a positive word and $\sim$ is a negation. A negative word will have positive polarity, if there is a negation word before or after this word e.g. مضر نبيـ (muzir nahi i.e. not harmful) or مضر بهى نهبي (muzir bhi nahi i.e. not harmful/hazardous) where مضر (muzir i.e. harmful) is a negative word and نبيب is a negation.

$$
\begin{aligned}
& \mathrm{W}_{\text {pol }}=\left\{-1, \text { if } \mathrm{S} \in \mathrm{B} \wedge \mathrm{W}_{1} \in \mathrm{W}_{\text {pos }} \mathrm{U} \mathrm{W}_{2} \in \mathrm{W}_{\text {expnegats }}\right\} \\
& \mathrm{W}_{\text {pol }}=\left\{-1, \text { if } \mathrm{S} \in \mathrm{B} \wedge \mathrm{W}_{1} \in \mathrm{W}_{\text {expnegats }} \mathrm{U}_{2} \in \mathrm{W}_{\text {pos }}\right\} \\
& \mathrm{W}_{\text {pol }}=\left\{1, \text { if } \mathrm{S} \in \mathrm{B} \wedge \mathrm{W}_{1} \in \mathrm{W}_{\text {neg }} \mathrm{U} \mathrm{W}_{2} \in \mathrm{W}_{\text {expnegats }}\right\}
\end{aligned}
$$




\section{Recognition and Effective Handling of Negations in Enhancing the Accuracy of Urdu Sentiment Analyzer}

$$
\mathrm{W}_{\text {pol }}=\left\{1 \text {, if } \mathrm{S} \in \mathrm{B} \wedge \mathrm{W}_{1} \in \mathrm{W}_{\text {expnegats }} \mathrm{U} \mathrm{W}_{2} \in \mathrm{W}_{\text {neg }}\right\}
$$

where $\mathrm{W}_{\text {pol }}$ is word polarity, $\mathrm{W}$ is a word, $\mathrm{S}$ is a sentence from $\operatorname{blog}(\mathrm{s}) \mathrm{B}$. $\mathrm{W}_{1}$ and $\mathrm{W}_{2}$ are neighbouring words (at times, there may be distance between $\mathrm{W}_{1}$ and $\left.\mathrm{W}_{2}\right)$.

Consider the following example:

$$
\begin{aligned}
& \text { اس ميس كوئى شكى نهيس كـ كجيه لوكون كا فطرتى طور }
\end{aligned}
$$

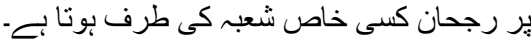

Iss mein koi shak nahi ke kuch logon ka fitrati tor par rujhaan kisi khaas shobaa ki taraf hota hai.

No doubt, some people have a natural tendency towards a particular discipline.

In (i), شكى (shak i.e. doubt) is a negative word but it is followed by the negation نبيي, so the combination of both will be assigned +1 .

(2) The positive or negative word will have the same polarity i.e. +1 for positive word and -1 for negative word, if there is صرف (sirf i.e. only) between the negation and the positive or negative word (i.e. negation followed by صرف e.g. نحرف (nah sirf i.e. not only).

$$
\begin{aligned}
& \mathrm{W}_{\mathrm{pol}}=\left\{1 \text {, if } \mathrm{S} \in \mathrm{B} \wedge \mathrm{W}_{1} \in \mathrm{W}_{\text {expnegats }} \mathrm{U} \mathrm{W}_{2} \in \mathrm{W}_{\mathrm{sw}} \mathrm{U}\right. \\
& \left.\mathrm{W}_{3} \in \mathrm{W}_{\text {pos }}\right\} \\
& W_{\text {pol }}=\left\{-1, \text { if } S \in B \wedge W_{1} \in W_{\text {expnegats }} U W_{2} \in W_{\text {sw }} U\right. \\
& \left.\mathrm{W}_{3} \in \mathrm{W}_{\text {neg }}\right\}
\end{aligned}
$$

where $\mathrm{W}_{1}, \mathrm{~W}_{2}$ and $\mathrm{W}_{3}$ are words one after another (at times, there may be distance between the words).

Consider the following example:

ان كى ذبنى صحت نـ صرف بهنر تهى بلكح ان كى كاركردگى ميل

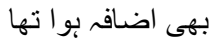

Un ki zehni sehat nah sirf behtar thi balkay un ki karkardagi mein bhi izafah howa tha.

They were not only mentally fit but their performance was also increased.

In the above example, بهيتر (behtar i.e. better) is a positive word and it remains positive in spite of the fact that it is preceded by the negation $\sim$, due to the presence of صرف (sirf i.e. only). So, collectively these three words i.e. نه صرف بهن (nah sirf behtar i.e. not only better), will be assigned +1. In other words, صرف (sirf i.e. only) cancel the effect of $\sim$.
(3) A positive word will have negative polarity and a negative word will have positive polarity, if there is a negation word after it, even in the presence of an intensifier.

$$
\begin{aligned}
& \mathrm{W}_{\text {pol }}=\left\{-1, \text { if } S \in \mathrm{B} \wedge \mathrm{W}_{1} \in \mathrm{W}_{\text {int }} \mathrm{U} \mathrm{W}_{2} \in \mathrm{W}_{\text {pos }} \mathrm{U}\right. \\
& \left.\mathrm{W}_{3} \in \mathrm{W}_{\text {expnegts }}\right\} \\
& \mathrm{W}_{\mathrm{pol}}=\left\{+1, \text { if } \mathrm{S} \in \mathrm{B} \wedge \mathrm{W}_{1} \in \mathrm{W}_{\mathrm{imt}} \mathrm{U} \mathrm{W}_{2} \in \mathrm{W}_{\text {neg }} \mathrm{U}\right. \\
& \left.\mathrm{W}_{3} \in \mathrm{W}_{\text {expnegts }}\right\}
\end{aligned}
$$

Consider the following example:

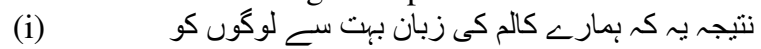
زياده سمجه نهيي آتى - لور

Nateeja yeh ke hamaray column ki zubaan bohat se logon ko ziyadah samajh nahi aati.

The end result is that most of the people do not understand the language of our article.

In this example, take the string of words زياده سمجه نهيي. Here, the words زياده (ziyadah i.e. more) is an intensifier, سمجه (samajh i.e. understand) is a positive نهيب (nahi i.e. no) is a negation. The three words will collectively be assigned the polarity of -1 . The intensifier has no effect here to increase or decrease the polarity.

(4) If the implicit negation e.g. كم (kam i.e. less) is preceded or followed by a positive word then its polarity from +1 will be changed to -1 . However, if this negation is preceded or followed by a negative word then the polarity -1 will be changed to +1 .

$$
\begin{aligned}
& \mathrm{W}_{\text {pol }}=\left\{-1, \text { if } S \in B \wedge \mathrm{W}_{1} \in \mathrm{W}_{\text {impnegts }} \mathrm{U}_{2} \in \mathrm{W}_{\text {pos }}\right\} \\
& \mathrm{W}_{\text {pol }}=\left\{-1, \text { if } S \in B \wedge \mathrm{W}_{1} \in \mathrm{W}_{\text {pos }} \mathrm{U} \mathrm{W}_{2} \in \mathrm{W}_{\text {impnegts }}\right\} \\
& \mathrm{W}_{\text {pol }}=\left\{1, \text { if } \mathrm{S} \in \mathrm{B} \wedge \mathrm{W}_{1} \in \mathrm{W}_{\text {impnegts }} \mathrm{U}_{2} \in \mathrm{W}_{\text {neg }}\right\} \\
& \mathrm{W}_{\text {pol }}=\left\{1, \text { if } \mathrm{S} \in \mathrm{B} \wedge \mathrm{W}_{1} \in \mathrm{W}_{\text {neg }} \mathrm{U} \mathrm{W}_{2} \in \mathrm{W}_{\text {impnegts }}\right\}
\end{aligned}
$$

Consider example (i) in Section "Implicit negation". In this example, the first occurrence of ظرف, which is a positive word, is followed by (i.e. an implicit negation), so collectively these words (i.e. ظرف ميب كم), will be assigned -1 .

\section{RESULTS AND DISCUSSION}

First, the algorithm is implemented by dealing with positive and negative words including nouns, verbs and adjectives without handling negations. In the input there are sentences with both simple and compound words. All sentences (with and without negations) in the corpus are given as input to the software system and the accuracy is calculated. Later on, the algorithm is improved for handling negations as well. To check 


\section{Recognition and Effective Handling of Negations in Enhancing the Accuracy of Urdu Sentiment Analyzer}

that the rules framed are working properly, all sentences are again provided to the system and the accuracy is recalculated. Table 2 shows a comparison of the accuracy of the system before and after handling negations.

\begin{tabular}{|c|c|c|c|c|}
\hline \multicolumn{5}{|c|}{ Table 2: Accuracy of Urdu Sentiment Analyzer before and } \\
after Handling Negations.
\end{tabular}

where Accuracy is the measurement of how close the estimated classification is to the actual classification.

Accuracy $=($ correctly classified sentences $/$ total number of sentences) $\times 100$

For evaluating the effectiveness and efficiency, accuracy alone is not sufficient performance metric. Therefore, the other three standard metrics i.e. Precision, Recall and F-measure are also computed.

where Precision $=T_{p} /\left(T_{p}+F_{p}\right)$

Number of True Positives divided by the sum of the number of True Positives and False Positives. $T_{p}$ stands for True Positive and $\mathrm{F}_{\mathrm{p} \text { for }}$ False Positive.

(The lower the Precision, the higher is the number of False Positives).

Recall $=T_{p} /\left(T_{p}+F_{n}\right)$

$\mathrm{F}_{\mathrm{n}}$ stands for False Negative

Number of True Positives divided by the sum of the number of True Positives and False Negatives. Recall is also called Sensitivity. The lower is the recall, the higher is the number of False Negatives.
F-measure $=(2 \times$ precision $\times$ recall $) /($ precision + recall).

This value ranges from 0 to 1 , the closer it is to 1 , the better is the result.

Table 3 shows the Precision, Recall and F-measure of the second phase (i.e. after handling negations) where $78.32 \%$ accuracy is achieved.

\begin{tabular}{|c|c|c|c|}
\hline \multicolumn{4}{|c|}{ Table 3: Precision, Recall and F-Measure of Urdu } \\
Sentiment Analyzer. \\
\hline $\begin{array}{c}\text { Metrics or } \\
\text { Classification }\end{array}$ & $\begin{array}{c}\text { Precision } \\
\text { (Float) }\end{array}$ & $\begin{array}{c}\text { Recall } \\
\text { (Float) }\end{array}$ & $\begin{array}{c}\text { F-measure } \\
\text { (Float) }\end{array}$ \\
\hline Positive & 0.861 & 0.823 & 0.841 \\
\hline Negative & 0.876 & 0.673 & 0.761 \\
\hline Neutral & 0.500 & 0.870 & 0.633 \\
\hline $\begin{array}{c}\text { Simple } \\
\text { average }\end{array}$ & 0.745 & 0.788 & 0.745 \\
\hline
\end{tabular}

From Table 3, it can be observed that much better results are achieved. These results are compared with the previous work done in Urdu Sentiment Analysis where negations are handled [29]. Table 4 shows this comparison.

\begin{tabular}{|c|c|c|c|}
\hline \multicolumn{3}{|c|}{ Table 4: Comparison with the previous work in Urdu } \\
Sentiment Analysis \\
\hline $\begin{array}{c}\text { Metrics/ } \\
\text { Set / Proposed } \\
\text { Analyzer }\end{array}$ & Precision & Recall & F-measure \\
\hline Syed et al. $[29]$ & & & \\
Set 1 & 0.864 & 0.837 & 0.850 \\
Set2 & 0.590 & 0.779 & 0.677 \\
Set3 & 0.510 & 0.615 & 0.558 \\
\hline Proposed Urdu & 0.745 & 0.788 & 0.745 \\
Sentiment Analyzer & 0.745 \\
\hline
\end{tabular}

The authors [29] took three sets from their collected corpus, in which Set1 includes the sentences without implicit and explicit negations. Set2 contains sentences with explicit negations and Set 3 considers sentences with both explicit and implicit negations. As we are interested particularly in negations, so we will focus on the results that are achieved with Set3 in which both negations are considered. Comparing the results achieved from Set3 and proposed Urdu Sentiment Analyzer, it is clear that the proposed Urdu Sentiment Analyzer is performing much better.

Few example sentences (with negations) along with their classifications as positive, negative or neutral sentence by the annotators are given:

i كيون زير آب آنه و الى آباديون كو بر وقت انتباه اور امدادفر ابم نـ كيا

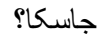

(Negative Sentence) 


\section{Recognition and Effective Handling of Negations in Enhancing the Accuracy of Urdu Sentiment Analyzer}

Kyun zair-aabb anay wali abadiyon ko bar-waqt intibah aur imdad faraham nah kya ja saka?

Why the flooded areas weren't given timely warning and relief?

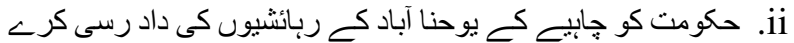

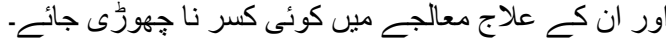

\section{(Positive Sentence)}

Hukoomat ko chahiye ke Youhana-abad ke rahaishion ki daad-rassi kare aur un ke ilaaj mualjay mein koi kasar naa choari jaye.

The government should support Youhanaabad'scitizens and spare no expense in their medical treatment.

\section{(Positive Sentence)}

$$
\text { - iii }
$$

Hum aap ki shaan mein koi gustaakhi nahi kartay.

We are not disrespecting you.

$$
\text { ملك بهر مين 60فيصد قيدى بغير عدالتى كاررو ائى كــ جيل ميل بند.iv }
$$

(Negative Sentence)

Mulk bhar mein 60 feesad qaidi baghair adalti karawai ke jail mein band rahay.

Sixty percent prisoners across the country were jailed without proper trial.

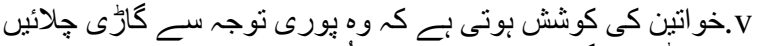

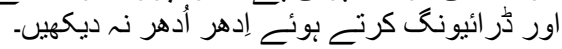$$
\text { (Positive Sentence) }
$$

Khawateen ki koshish hoti hai ke who poori tawajah se gaari chalayein aur driving karte hue idher udhar nah dekhen.

Women try their best to drive the car with full attention without looking around.

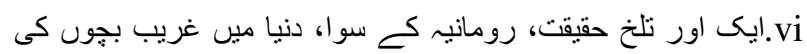

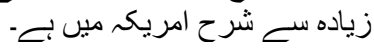

\section{(Negative Sentence)}

Aik aur talkh haqeeqat, Romania ke siwa, duniya mein ghareeb bachon ki ziyadah se sharah America mein hai.

Another bitter fact is that in America, the percentage of poor children is the second highest after Romania.

سوجنا بوب، نهبي نهبي خر ابيان سب كـ سامنه لائى جانى جابئيس. vii

(Positive Sentence)

Sochta hoon, nahi nahi kharabian sab ke samnay layi jani chahiye.

I think deficiencies should be publicly known.

\section{(Negative Sentence)}

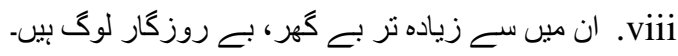

Un mein se ziyadah tar be-ghar, be-rozgaar log hain.

Most of these people are homeless and unemployed.

ix

\section{(Negative Sentence)}

Doosri barri wajah yeh hai ke Pakistanio ke liye sehatmand tafreeh ke mawaqay bohat kam ho chuke hain . The second main reason is that healthy recreational opportunities for Pakistanis are quite reduced.

\section{(Neutral Sentence)}

$$
\text { X ديكهي نا بهُى-.X. X }
$$

Dekhen naa bhae

Just see.

Fig.1 shows the same sentences (discussed above) from different blogs (with negations), that are given as input to the Urdu Sentiment Analyzer, and the output provided by the system.

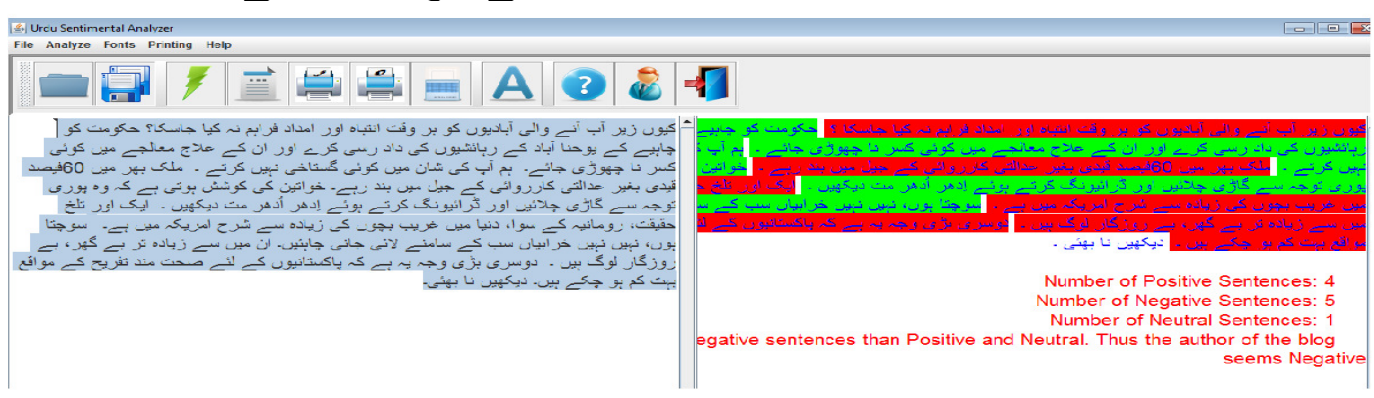

FIG. 1: CLASSIFIED SENTENCES AS POSITIVE, NEGATIVE AND NEUTRAL 
In Fig.1, the output provided by Urdu Sentiment Analyzer is displayed, where the sentences are highlighted in different colors. The red highlighting is used for negative sentences, the green highlighting is used for positive sentences and the white highlighting is used for neutral sentences. It can be observed that all the sentences with negations are correctly identified. Fig. 2 shows the same output by means of a pie-chart and Fig. 3 shows the descriptive statistics generated by the system.

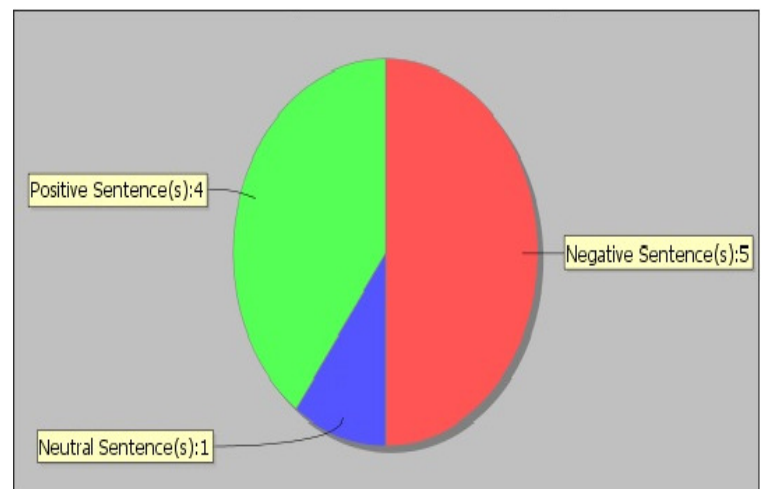

FIG. 2: OUTPUT OF THE URDU SENTIMENT ANALYZER

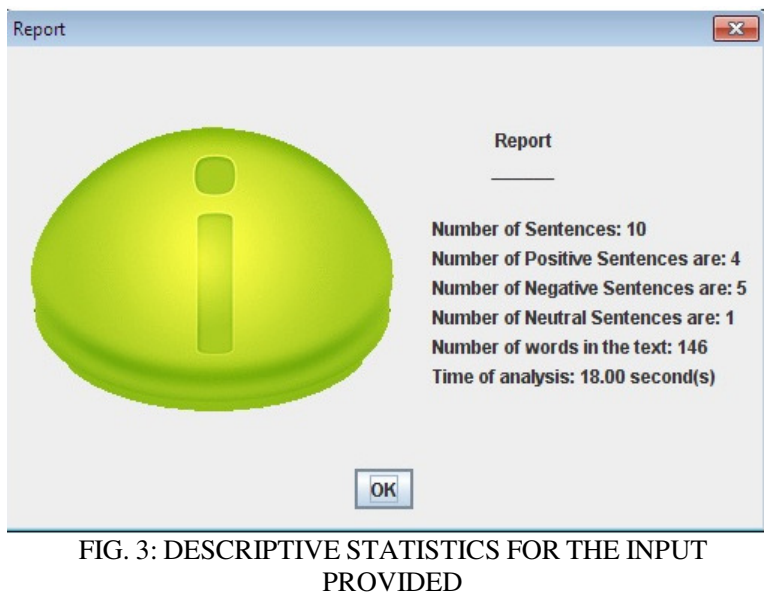

To check that the performance of Urdu Sentiment Analyzer after incorporating rules for handling negations, is significant or not, McNemar's test [32] is applied.

For testing, Urdu Sentiment Analyzer without handling negations is considered as classifier 1 and the same analyzer after handling negations is considered as classifier 2. To check that the two classifiers are statistically significant, McNemar's Test is applied. The sampling distribution of the McNemar statistic has a Chi-square distribution.

\begin{tabular}{|l|l|}
\hline $\mathrm{n}_{00}$ & $\mathrm{n}_{01}$ \\
\hline $\mathrm{n}_{10}$ & $\mathrm{n}_{11}$ \\
\hline
\end{tabular}

where $\mathrm{n}_{00}$ represents the number of instances correctly classified by both the classifiers. $\mathrm{n}_{11}$ represents the number of instances misclassified by both the classifiers. $\mathrm{n}_{01}$ represents the number of instances correctly classified by classifier 1 but misclassified by classifier 2. $\mathrm{n}_{10}$ represents the number of instances correctly classified by classifier 2 but misclassified by classifier 1.

$\mathrm{M}=\left(\mathrm{n}_{01}-\mathrm{n}_{10}\right)^{2} /\left(\mathrm{n}_{01}+\mathrm{n}_{10}\right)$

where $\mathrm{M}$ denotes the test statistic, McNemar's Test.

The null hypothesis $\left(\mathrm{H}_{\mathrm{o}}\right)$ : The two classifiers are equal.

Alternative hypothesis $\left(\mathrm{H}_{1}\right)$ : The two classifiers differ significantly.

Significance level $(\alpha)=0.05 \quad(95 \%$ confidence interval).

The critical value for the $\mathrm{McNemar}$ statistic $=3.84$.

The null hypothesis is not rejected if the McNemar statistic is less than 3.84 or p-value is greater than 0.05 . The null hypothesis is rejected if the McNemar statistic is greater than 3.84 or p-value is less than 0.05 . Rule of thumb is: $\mathrm{n}_{01}+\mathrm{n}_{10}$ is greater than or equal to 20.

For applying McNemar's Test, 720 sentences are randomly selected from the collected corpus and are tested by both the classifiers. Table 5 shows the classification detail by the two classifiers.

\begin{tabular}{|c|c|}
\hline TABLE 5: CLASSIFICATION BY THE TWO CLASSIFIERS \\
\hline $\mathrm{n}_{0}=523$ & $\mathrm{n}_{01}=42$ \\
\hline $\mathrm{n}_{10}=07$ & $\mathrm{n}_{11}=148$ \\
\hline
\end{tabular}

After substituting the values in equation (5), the resulting value of the test statistic i.e. McNemar's Test, is greater than 3.84 and p-value is less than 0.05 . The difference between the two classifiers is statistically significant. Thus the performance of Urdu Sentiment Analyzer is significantly improved after handling negations. 


\section{CONCLUSION}

The paper shows that negations play an important role in the correct classification of sentences. Negation handling for Urdu language is the main focus of this research work. Rules are formulated for the three forms of negations i.e. morphological, implicit and explicit negations and software is developed to handle them effectively. Sentences from the corpus are tested for computing the accuracy of the system. The system classified the sentences correctly (as positive, negative or neutral sentence). A comparison in terms of accuracy is presented before and after handling negations. The accuracy of the system after dealing with negations is increased by almost $5 \%$ compared to its previous version which is statistically significant improvement for correct classification of sentences.

\section{ACKNOWLEDGMENT}

Authors acknowledge Department of Computer Scien ce, University of Peshawar, Pakistan for the motivation and support in the successful completion of this research work. Authors are particularly grateful to Mr. Al-Gaili, MS Computer Science, University of Peshawar, for his valuable suggestions, discussions and help throughout this research.

\section{REFERENCES}

[1] Wiegand, M., Balahur, A., Roth, B., Klakow, D., and Montoyo, A., "A Survey on the Role of Negation in Sentiment Analysis ", Proceedings of the International Conference on Negation and Speculation in Natural Language Processing, Stroudsburg, pp. 60-68, 2010.

[2] Hogenboom, A., Van Iterson, P., Heerschop, B., Frasincar, F., and Kaymak, U., "Determining Negation Scope and Strength in Sentiment Analysis", Proceedings of the IEEE International Conference on Systems, Man, and Cybernetics, pp. 2589-2594, 2011.

[3] Wilson, T., Wiebe, J., and Hoffmann, P., "Recognizing Contextual Polarity: An Exploration of Features for Phrase-Level Sentiment Analysis", Computational Linguistics, Vol. 35, No. 3, pp. 399-433, 2009.
[4]

Wilson, T., Wiebe, J., and Hoffmann, P., "Recognizing Contextual Polarity in PhraseLevel Sentiment Analysis", Proceedings of the International Conference on Human Language Technology and Empirical Methods in Natural Language Processing, Canada, pp. 347-354, 2005.

[5] Horn, L.R., and Kato, Y., "Negation and Polarity at the Millennium", Introduction to Negation and Polarity: Syntactic and Semantic Perspectives, Horn and Kato ed: Negation and Polarity, Oxford U. Press, pp. 1-19, 2000.

[6] Pr"ollochs, N., Feuerriegel, S., and Neumann, D., "Enhancing Sentiment Analysis of Financial News by Detecting Negation Scopes", Proceedings of the $48^{\text {th }}$ Hawaii International Conference on System Sciences, pp. 959-968, 2015.

[7] Loughran, T., and McDonald, B., "When is a Liability Not a Liability? Textual Analysis, Dictionaries, and 10-Ks", The Journal of Finance, Vol. 66, No. 1, pp. 35-65, 2011.

[8] Loughran, T., and McDonald, B., "IPO FirstDay Returns, Offer Price Revisions, Volatility, and Form S-1 Language", Journal of Financial Economics, Vol. 109, No. 2, pp. 307-326, 2013.

[9] Reitan, J., Faret, J., Gambäck, B., and Bungum, L., "Negation Scope Detection for Twitter Sentiment Analysis", Proceedings of the 6th Workshop on Computational Approaches to Subjectivity, Sentiment and Social Media Analysis, Lisboa, Portugal, pp. 99-108, 2015.

[10] Sharif, W., Samsudin, N.A., Deris, M.M., Naseem, R., and Mushta, M.F., "Effect of Negation in Sentiment Analysis", International Journal of Computational Linguistics Research, Vol. 8, No.2, pp. 4756, 2017.

[11] Farooq, U., Mansoor, H., Nongaillard, A., Ouzrout, Y., and Qadir, M.A., "Negation Handling in Sentiment Analysis at Sentence Level", Journal of Computers, Vol. 12, No. 5, pp. 470-478, 2017.

[12] Syed, A.Z., "Redefining Urdu Morphology and Grammar for the Development of an 
Integrated Sentiment Analysis Framework", Ph.D. Thesis, Department of Computer Science and Engineering, University of Engineering and Technology Lahore, Pakistan, 2013.

[13] Jia, L., Yu, C., and Meng, W., "The Effect of Negation on Sentiment Analysis and Retrieval Effectiveness", Proceedings of the $18^{\text {th }}$ ACM Conference on Information and Knowledge Management, Hong Kong, China, pp. 1827-1830, 2009.

[14] Dave, K., Lawrence, S., and Pennock, D.M., "Mining the Peanut Gallery: Opinion Extraction and Semantic Classification of Product Reviews", Proceedings of the $12^{\text {th }}$ International World Wide Web conference (WWW 2003), Budapest, pp. 519-528, 2003.

[15] Boiy, E., and Moens, M.-F., "A Machine Learning Approach to Sentiment Analysis in Multilingual Web Texts", Information Retrieval, Vol. 12, No. 5, pp. 526-558, 2008.

[16] Taboada, M., Brooke, J., Tofilosk, M., Voll, K., and Stede, M., "Lexicon Based Methods for Sentiment Analysis", Computational Linguistics, Vol. 37, No. 2, pp. 267-307, 2011.

[17] Pang, B., Lee, L., and Vaithyanathan, S., "Thumbs Up? Sentiment classification Using Machine Learning", Proceedings of the Conference on Empirical Methods in Natural Language Processing, pp. 79-86, 2002.

[18] Polanyi, L., and Zaenen, A., "Contextual Valence Shifters", Computing Attitude and Affect in Text: Theory and Applications, Y. Q. J.G. Shanahan, \& J. Wiebem Ed. Dordrecht, the Netherlands: Springer Netherlands, pp. 1-10, 2006.

[19] Carrillo-de-Albornoz, J., and Plaza, L., "An Emotion-Based Model of Negation, Intensifiers, and Modality for Polarity and Intensity Classification", Journal of the American Society for Information Science and Technology, Vol. 64, No. 8, pp. 16181633, 2013.

[20] Asmi, A., and Ishaya, T., "Negation Identification and Calculation in Sentiment Analysis", Proceedings of the Second International Conference on Advances in
Information Mining and Management, pp. 17, 2012.

[21] Rafique, A., Malik, M.K., Nawaz, Z., Bukhari, F., and Jalbani, A.H., "Sentiment Analysis for Roman Urdu", Mehran University Research Journal of Engineering and Technology, Vol. 38, No. 2, pp. 463-470, 2019.

[22] Muaz, A., Ali, A., and Hussain, S., "Analysis and Development of Urdu POS Tagged Corpora", Proceedings of the $7^{\text {th }}$ Workshop on Asian Language Resources, ACLIJCNLP, Suntec, Singapore, pp. 24-31, 2009.

[23] Humayoun, M., Hammarström, H., and Ranta, A., "Urdu Morphology, Orthography and Lexicon Extraction", Proceedings of the $2^{\text {nd }}$ Workshop on Computational Approaches to Arabic Script-Based Languages, Stanford, USA, pp. 59-66, 2007.

[24] Ijaz, M., and Hussain, S., "Corpus Based Urdu Lexicon Development", Proceedings of the Conference on Language Technology, University of Peshawar, Pakistan, pp. 85-94, 2007.

[25] Mukund, S., Ghosh, D., and Srihari, R., "Using Cross-Lingual Projections to Generate Semantic Role Labeled Corpus for Urdu-A Resource Poor Language", Proceedings of the $23^{\text {rd }}$ International Conference on Computational Linguistics, Beijing, pp. 797-805, 2010.

[26] Syed, A.Z., Muhammad, A., and Enríquez, A.M.M., "Lexicon Based Sentiment Analysis of Urdu Text Using SentiUnits", Proceedings of the 9th Mexican International Conference of Artificial Intelligence, MICAI, Berlin Heidelberg, pp. 32-43, 2010.

[27] Daud, M., Khan, R., and Duad, A., "Roman Urdu Opinion Mining System (RUOMiS)", CSEIJ, Vol. 4, No. 6, pp. 1-9, 2014.

[28] Rehman, Z.U., and Bajwa, I.S., "LexiconBased Sentiment Analysis for Urdu Language ", Proceedings of the Sixth International Conference on Innovative Computing Technology, pp. 497-501, 2016.

[29] Syed, A.Z., Muhammad, A., and Enríquez, A.M.M., "Sentiment Analysis of Urdu language: Handling Phrase-Level Negation", 
Proceedings of the $10^{\text {th }}$ Mexican International Conference of Artificial Intelligence, pp. 382393, 2011.

[30] Mukhtar, N., and Khan, M.A., "Urdu Sentiment Analysis Using Supervised Machine Learning Approach", International Journal of Pattern Recognition and Artificial intelligence, Vol. 32, No. 1, pp. 1851001-115,2018

[31] Mukhtar, N., Khan, M.A., and Chiragh, N., "Lexicon-Based Approach Outperforms Supervised Machine Learning Approach for Urdu Sentiment Analysis in Multiple Domains", Telematics and Informatics, Vol. 35, No. 8, pp. 2173-2183, 2018.

[32] Bostanci, B., and Bostanci, E., "An Evaluation of Classification Algorithms Using Mc Nemar's Test", Proceedings of the Seventh International Conference on BioInspired Computing: Theories and Applications, New Delhi, India, pp. 15-26, 2013. 